\title{
LIMITES DE EXPOSIÇÃO OCUPACIONAL DAS NORMATIVAS BRASILEIRAS DE SAÚDE E SEGURANÇA EM TRABALHOS COM BAIXAS TEMPERATURAS
}

\section{OCCUPATIONAL EXPOSURE LIMITS OF REGULATORY HEALTH AND SAFETY AT WORK OF BRAZILIAN WITH LOW TEMPERATURES}

\author{
Fabiano Takeda * e-mail: takeda.f@bol.com.br \\ Antônio Renato Pereira Moro * e-mail: renato.moro@ufsc.br \\ *Universidade Federal de Santa Catarina (UFSC), Florianópolis, SC.
}

\begin{abstract}
Resumo: O objetivo do estudo foi analisar os resultados de imagens termográficas da superfície da pele de partes do corpo de trabalhadores expostos a atividades com baixas temperaturas em um setor de cortes de frangos e comparar com os limites de tolerância das leis e normas regulamentadoras de saúde e segurança nacionais. Foram realizadas avaliações termográficas nas mãos e pés dos trabalhadores e avaliações na sala de trabalho conforme determina as normas regulamentadoras. As avaliações demonstram que os resultados ambientais atendem aos requisitos legais das normativas brasileiras de saúde e segurança, porém foram encontradas temperaturas nos dedos dos pés e das mãos que comparados aos parâmetros fisiológicos demostram condições que podem causar desconforto por resfriamento, dormência, dor, disfunções neuromusculares, surgimento de lesões e doenças provocadas por baixas temperaturas. Conclui-se que as leis e normas nacionais para a exposição ao frio determinam critérios insuficientes para manter o controle e preservação da saúde e integridade de pessoas em atividades com exposição a baixas temperaturas, resultando em implicações práticas de avaliação e de controle da exposição aos riscos.
\end{abstract}

Palavras-chave: Temografia. Matadouro. Normas Regulamentadoras. Frio.

Abstract: The objective of the study was to analyze the results of thermographic images of the skin surface of parts of the body of workers exposed to low temperature activities in a sector of cuts of chickens and to compare with the limits of tolerance of the laws and norms regulating health and safety national authorities. Thermographic evaluations were performed on the hands and feet of workers and evaluations in the work room as determined by regulatory standards. The evaluations demonstrate that the environmental results meet the legal requirements of the Brazilian health and safety regulations, but temperatures on the toes and hands were found that, compared to the physiological parameters, show conditions that can cause discomfort due to cooling, numbness, pain, neuromuscular dysfunctions, onset of lesions and diseases caused by low temperatures. It is concluded that national laws and regulations for exposure to cold determine insufficient criteria to maintain the control and preservation of the health and integrity of people in activities with exposure to low temperatures, resulting in practical implications for the assessment and control of exposure to risks.

Keywords: Thermography. Slaughterhouse. Regulatory standards. Cold.

\section{INTRODUÇÃO}

Empresas de diversos ramos industriais, como frigoríficos, indústrias alimentícias e portuárias, expõem trabalhadores ao frio devido à necessidade de 
manter a qualidade e conservação dos produtos visando atender as normas higiênico-sanitárias obrigatórias para produção de alimentos perecíveis. De acordo com Geng (2001) podem ser considerados ambientes frios os locais com temperatura menores de $20^{\circ} \mathrm{C}$.

Em virtude dessas exposições a baixas temperaturas, se não forem controlados adequadamente a exposição dos trabalhadores, o resultado pode ser 0 aumento significativo de doenças e acidentes de trabalho (ASSUNÇÃO; AMEIDA, 2003; QUEIROZ; MACIEL, 2001).

Segundo dados do Ministério da Agriculta Pecuária e Abastecimento MAPA (2016) e do Instituto Brasileiro de Geografia e Estatística IBGE (2016) a indústria brasileira de abate e processamento de frangos apresenta constante crescimento nas últimas décadas, apresenta-se como o terceiro maior produtor mundial de frangos com destaque na exportação, fornecendo carne de frango para cerca de 150 países, respondendo por $1,8 \%$ do Produto Interno Bruto (PIB) nacional. A expectativa é que, até 2020 , a produção nacional de frango alcance $48,1 \%$ das exportações mundiais.

Esses dados representam o expressivo número de empresas frigoríficas e abatedouros de frangos em atividade no território brasileiro. Em função deste cenário, a necessidade de mão de obra para atender a demanda produtiva torna-se elevada. Segundo a União Brasileira de Avicultura, a UBABEF (2016) a avicultura emprega aproximadamente 3,6 milhões de pessoas, direta e indiretamente.

Em contrapartida ao crescimento positivo dos números de produção da carne de frango, é apontada uma grave problemática em relação às condições de saúde dos trabalhadores que atuam diretamente nas plantas frigoríficas, evidenciada através de estudos nacionais e internacionais que relatam a diversidade de riscos físicos (ruído, temperaturas extremas, umidade, vibração), químicos, biológicos e ergonômicos presentes nas atividades de abate e processamento de frangos e outros animais (DEJOURS; ABDOUCHELI; JAYET, 1994; BONDE et al., 2003; CASO; RAVAIOLI; VENERI, 2007; JAKOBI et al, 2015; ARMSTRONG et al, 1993; BAO; SILVERSTEIN; COHEN, 2001; BUSNELLO; DEWES, 2013; FROST; ANDERSEN; NIELSEN, 1998; HECK, 2013; JUUL-KRISTENSEN et al., 2002; MUSOLIN et al., 2014; SOMMERICH; MCGLOTHLIN; MARRAS, 1993; SUNDSTRUP et al. 2013; SUNDSTRUP et al. 2014). 
As atuais estimativas nacionais da Previdência Social reportam que há um elevado índice, cuja média atinge $23 \%$ da mão de obra do setor frigorífico, na condição de afastados do trabalho ou no aguardo de decisões judiciais em função de acidentes e doenças ocupacionais (INSS, 2016).

Em destaque a exposição a condições de risco a saúde e integridade, está à exposição ao frio que ocorre de forma continua para a maioria dos trabalhadores de frigoríficos e abatedouros, e para agravar a exposição ao frio, as atividades são de forma estática que diminuem a geração de calor do corpo, pois o processo produtivo ocorre de forma sequencial, com maior enfoque na movimentação dos membros superiores (REIS, 2012; SARDÁ; RUIZ; KIRTSCHIG, 2009; ILMARINEN; TAMMELA, 1990).

A exposição ao frio acaba se tornando inevitável em função da necessidade de atendimento da Portaria 210 de 10/11/1998 do Ministério da Agricultura e do Abastecimento do Brasil que estabelece limites para a sala de cortes de frangos, instruindo que a temperatura do frango não pode ser superior à $7^{\circ} \mathrm{C}$, e a temperatura do ambiente não pode ser superior aos 12으 (PORTARIA № 210 do SIF, 1998).

Consecutivamente estudos em frigoríficos apontam a prevalência de queixas de dor e desconforto em trabalhadores da indústria frigorífica em relação ao frio do ambiente de trabalho, e essas queixas predominam nas mãos devido o modelo de atividade e contato com as peças de frangos resfriadas e/ou congeladas (BUZANELLO; MORO, 2012; BUZANELLO, 2003; HOLMÉR, 1994).

Consequentemente podem ocorrer sintomas como estresse, desconforto, dormência, rigidez nas partes com maior intensidade de exposição ao frio, redução da destreza, formigamento, redução da sensibilidade dos dedos e flexibilidade das articulações, entre outras anomalias, aumentando consequentemente e predispondo os trabalhadores expostos a essas condições em riscos de acidentes e principalmente problemas de saúde (SARDÁ; RUIZ; KIRTSCHIG, 2009; ARAUJO, 2013; IIDA, 2005; HASSI, 2001).

A determinação de medidas que atendam as normativas de conservação do produto é imprescindível para garantir a higiene alimentar e qualidade do produto, todavia, deve haver equilíbrio, para que as variáveis de conforto, segurança e saúde do trabalhador sejam atendidas assim como as normas de higiene alimentar. 
A legislação brasileira profere que o empregador deve garantir que 0 ambiente de trabalho não expõe a riscos à saúde e segurança de seu empregado, visto que é de direito desses, a redução e controle dos riscos inerentes ao trabalho, por meio de normas de saúde, higiene e segurança (CASTRO; OKAWA, 2016). Nesse contexto, a legislação brasileira para preservação da saúde e integridade física do trabalhador exposto ao frio ocupacional é composta por normas e leis trabalhistas.

A norma regulamentadora NR 15 - Atividade e operações insalubres cita em seu anexo 9, específico para exposição ao frio, que as atividades ou operações executadas no interior de câmaras frigoríficas, ou em locais que apresentem condições similares, que exponham os trabalhadores ao frio, sem a proteção adequada, serão consideradas insalubres em decorrência de laudo de inspeção realizada no local de trabalho (MTE, 2016).

A norma regulamentadora NR 29 cita que em locais frigorificados a jornada de trabalho deve obedecer a uma tabela com cinco faixas de temperatura de bulbo seco $\left({ }^{\circ} \mathrm{C}\right)$ de máxima exposição ao frio para pessoas adequadamente vestidas (MTE, 2016).

O Decreto Lei no 5.452 de 01 de Maio de 1943 da CLT - Consolidação das Leis Trabalhistas considera o Art. 253 - que cita que para os empregados que trabalham no interior das câmaras frigoríficas e para os que movimentam mercadorias do ambiente quente ou normal para o frio e vice-versa, depois de 1 (uma) hora e 40 (quarenta) minutos de trabalho contínuo, será assegurado um período de 20 (vinte) minutos de repouso, computado esse intervalo como de trabalho efetivo.

Especificamente para abatedouros e frigoríficos, em 18 de abril de 2013 foi criada a última norma regulamentadora atualmente, publicada pela Portaria do Ministério do Trabalho e Emprego, a norma regulamentadora NR 36 a qual refere-se que os trabalhadores que exercem suas atividades em ambientes artificialmente frios e para os que movimentam mercadorias do ambiente quente ou normal para o frio e vice-versa, depois de uma hora e quarenta minutos de trabalho contínuo, será assegurado um período mínimo de vinte minutos de repouso, nos termos do Art. 253 da CLT, considerando o Parágrafo único, das zonas climáticas do mapa do IBGE (MTE, 2016). 
A norma regulamentadora NR 09, em seu subitem 9.3.5.1 descreve que deverão ser adotadas medidas para eliminação, minimização ou controle dos riscos ambientais quando os resultados das avaliações quantitativas da exposição dos trabalhadores excederem os valores dos limites previstos na NR-15 ou, na ausência destes os valores limites de exposição ocupacionais adotados pela ACGIH American Conference of Governmental Industrial Higyenists, ou aqueles que venham a ser estabelecidos em negociação coletiva de trabalho, desde que mais rigorosos do que os critérios técnico-legais estabelecidos (MTE, 2016).

Ressalta-se que o objetivo da ACGIH é apresentar um TLV - Threshold Limit Values para impedir que a temperatura interna do corpo reduza abaixo dos $36^{\circ} \mathrm{C}$ $\left(96,8^{\circ} \mathrm{F}\right)$ e prevenir lesões pelo frio nas extremidades do corpo (considera a temperatura interna a do núcleo do corpo determinada por métodos convencionais de medição da temperatura retal) (ACGIH, 2015).

Considerando o contexto das normas e leis nacionais o objetivo desse estudo foi analisar os resultados de imagens termográficas da superfície da pele de partes do corpo de trabalhadores expostos a baixas temperaturas em um setor de cortes de frangos e comparar com os limites de tolerância propostos pelas leis e normas regulamentadoras de saúde e segurança nacionais.

\section{MATERIAIS E METÓDOS}

A pesquisa sempre parte de um tipo de problema, de uma interrogação (LAKATOS; MARCONI, 2007). Partindo desse conceito, buscou-se com esta pesquisa analisar se as condições de trabalho avaliadas nesse estudo atendem as normativas nacionais e se as condições de trabalho expõem os trabalhadores a condições de riscos a saúde ocupacional. O estudo foi realizado no setor de cortes de um abatedouro de frangos localizado na região de Santa Catarina.

Quanto ao universo e amostra, a pesquisa foi realizada com dados de monitoramento ambiental coletados em um setor de cortes de frangos e com dados de análises termográficas realizadas em regiões do corpo conforme critérios da ISO 11079:2007 - Ergonomics of the Thermal Environment. Também foram analisados o programa de prevenção de riscos ambientais (PPRA) e laudo de insalubridade das atividades e do setor avaliados no estudo para comparar os limites de tolerância 
propostos pelas leis e normas regulamentadoras de saúde e segurança nacionais com os valores encontrados nas avaliações coletadas no estudo.

Os dados de monitoramento ambiental que representam as condições do setor e os dados de temperaturas das mãos e pé dos trabalhadores foram coletados simultaneamente após 1 (uma) hora e 40 (quarenta) minutos de trabalho contínuo de exposição ao frio, pois o maior tempo de exposição continua que ocorre nesse modelo de atividade avaliado na empresa em estudo é de aproximadamente 2 (duas) horas para atender a determinação obrigatória de tempo máximo de trabalho descrita na NR 36 (MTE, 2016).

Para realização do estudo foi disponibilizado próximo ao setor avaliado uma sala com temperatura ambiente média de $23,7^{\circ} \mathrm{C}$, esta temperatura foi medida com um medidor de estresse térmico marca Instrutherm, modelo TGD-300.

Para avaliação das temperaturas superficiais nas regiões corporais foi utilizado um termovisor, modelo E40, range de temperatura de -20 a $650^{\circ} \mathrm{C}$, com parâmetros de calibração de 0,98 de emissividade (corpo humano), $20^{\circ} \mathrm{C}$ de temperatura refletida e $80 \%$ de umidade relativa. O equipamento foi instalado em um tripé a $85 \mathrm{~cm}$ do chão e $100 \mathrm{~cm}$ de distância de uma placa de tecnil utilizada como anteparo para as mãos, centralizada em uma mesa, e posteriormente com a mesma placa de tecnil, posicionada no chão da sala foi registrado a fotografia do pé direito de cada trabalhador. A dimensão da placa utilizada é $30 \mathrm{~cm}$ de largura por $25 \mathrm{~cm}$ de altura.

Cada trabalhador participante da pesquisa foi retirado da linha de produção e encaminhado para a sala de avaliação que fica próxima aos setores de trabalho das funcionárias que fizeram parte do estudo, o percurso foi de aproximadamente 25 segundos do posto de trabalho até a sala. Cada participante foi retirada e acompanhada no percurso de ida e volta entre posto de trabalho e sala de avaliação. Durante o percurso foram orientadas a não tocar as mãos em nenhuma parte do corpo e não podiam retirar as luvas. Ao chegar à sala o procedimento consistia em retirar as luvas utilizadas para proteção dos riscos inerentes a atividade, elevar as mangas da blusa e posicionar as mãos na frente da placa de tecnil para registrar as fotos das mãos, conforme representado no lado esquerdo da Figura 1, em seguida retirar a botina e meia para registrar a foto do pé, conforme representado no lado direito da Figura 1. 
Figura 1 - Posicionamento dos equipamentos e do indivíduo no aparato de coleta de imagens

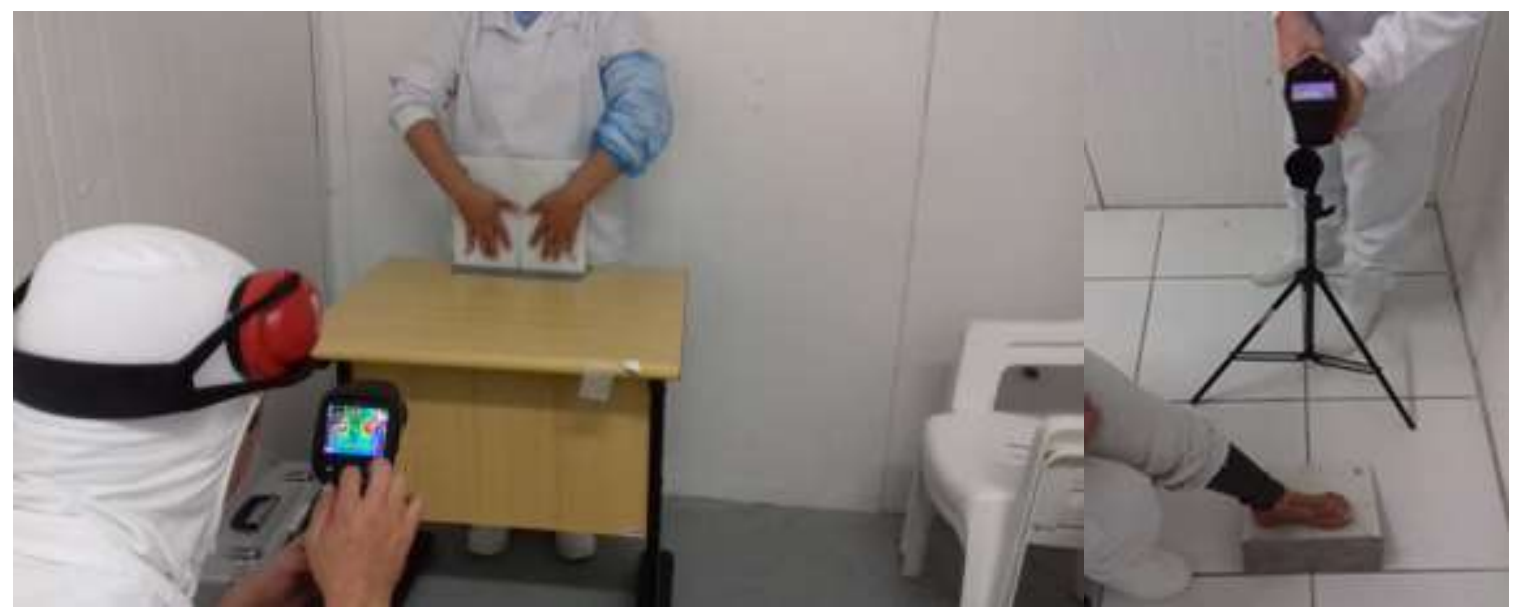

Fonte: Dados da pesquisa (2016)

A única premissa adotada no estudo foi que os trabalhadores deveriam fazer parte do quadro da empresa e do setor por mais um mês. As avaliações foram exclusivas com mulheres, em função de não haver homens trabalhando nos cortes do setor selecionado para pesquisa. Atualmente, em média, $41 \%$ do efetivo da empresa desenvolvem suas atividades em salas com temperaturas similares que variam entre $-2^{\circ} \mathrm{C}$ e $+2^{\circ} \mathrm{C}$ da temperatura da sala avaliada, e nestes setores em média $62 \%$ correspondem ao sexo feminino.

Após o registro das fotos a análise dos dados e geração de informações foram realizadas no software QuickReport do equipamento Flir E40, licenciado pela Flir Systems AB da Microsoft Licensing. O software forneceu temperaturas mínimas, máximas e médias de cada ponto corporal selecionado. Para análise dos resultados das mãos foram consideradas as temperaturas médias representadas nos pontos 1 , 2, 3, 4, 5 e 6 representado com as mãos de um participante do estudo, lado esquerdo da Figura 2 e respectivamente, sendo todas localizadas no lado dorsal de ambas as mãos. Para análise dos resultados do pé avaliado de cada trabalhador foram consideradas as temperaturas médias representadas pelos pontos 1, 2, 3 e 4 conforme lado direito da Figura 2. 
Figura 2 - Imagens das regiões corporais analisadas no estudo

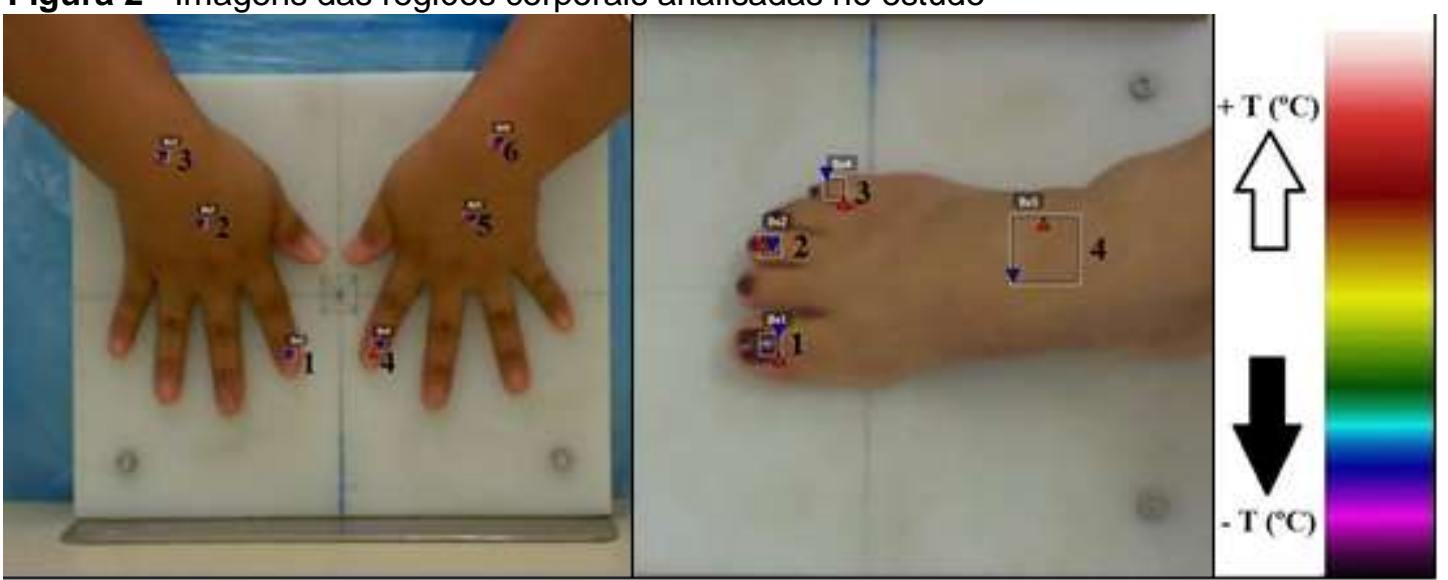

Fonte: Dados da pesquisa (2016)

Os pontos corporais avaliados nas mãos e pé foram selecionados fundamentados na ISO 11079: 2007 "Ergonomics of the termal environment" a qual não determina pontos específicos a serem avaliados para exposições ao frio localizado, mas recomenda controle frequente de temperatura dos dedos e sugere que as temperaturas devem estar acima de $24^{\circ} \mathrm{C}$ para a preservação e bom funcionamento das mãos. Também determina que a quantidade de conhecimento sobre as respostas a resfriamento local é insuficiente para o desenvolvimento de um metódo de avaliação único e que pesquisas sobre o assunto devem ser incentivadas (ISO 11079: 2007).

Para análise dos dados foi diferenciada a mão que segura à faca da mão que segura o produto a ser cortado. Essa diferenciação entre as mãos é importante devido à diferença de temperatura da faca e do produto. O pé foi avaliado apenas o lado direito, pois não foram encontradas diferenças de temperatura no piso do posto de trabalho e entre as botinas e meias de ambos os pés (direito e esquerdo).

Os trabalhadores estavam utilizando, na mão que segura o produto luva látex sobreposta com luva malha de aço e na mão que segura à faca, luva de algodão sobreposta com luva látex. Nos pés, utilizam meia de algodão e botina de PVC. Todos os equipamentos de proteção são cedidos pela empresa.

As imagens da termografia mostram a distribuição de temperatura nas mãos e pé, especificamente nas regiões corporais de interesse, através de um espectro de cores e valores que pode ser calibrados conforme o modelo de equipamento 
utilizado. No estudo foi utilizada a escala representada na lateral direita da Figura 2, onde o tom preto é associado a menor temperatura (próxima a $10^{\circ} \mathrm{C}$ ) e o tom branco referente à maior temperatura (próxima a $33^{\circ} \mathrm{C}$ ).

Como parâmetros para análise dos resultados foi utilizado uma adaptação das escalas de temperatura, baseada no estudo conduzido por Lehmuskallio, Hassi e Kettunen (2002), onde a faixa de temperatura entre $36-34^{\circ} \mathrm{C}$ indica condição de conforto térmico, entre $33,9-29^{\circ} \mathrm{C}$ indica condição neutra, entre $28,9-25^{\circ} \mathrm{C}$ indica desconforto (resfriado), entre $24,9-18^{\circ} \mathrm{C}$ indica sensação de desconforto (frio), entre $17,9-12^{\circ} \mathrm{C}$ indica sensação de dor provocada pelo frio, entre $11,9-8^{\circ} \mathrm{C}$ indica sensação de dor e formigamento (perda gradual da percepção tátil) e menor de $8^{\circ} \mathrm{C}$ indica sensação de dor e congelamento.

Para mensuração da temperatura superficial do cabo da faca, do produto manipulado e do piso foi utilizado um termômetro digital infravermelho marca Minipa, modelo MT-350. Para medir a velocidade do ar nas salas foi utilizado termo-higroanemômetro marca Instrutherm, modelo THAR-200.

Durante todo o tempo de trabalho, a posição dos trabalhadores é em ortostase, estática e as atividades desenvolvidas consiste em pegar e manipular as peças de frango com uma das mãos, de forma que facilite o direcionamento do corte com a faca sustentada com a mão contrária.

Essa pesquisa foi autorizada pelo representante legal da empresa que concedeu o local para realizar as avaliações e todas as funcionárias participantes aceitaram o termo de consentimento livre esclarecido conforme protocolo da pesquisa, submetida e aprovada pela Comissão de Ética em Pesquisa da Universidade Federal de Santa Catarina, atendendo a todas as recomendações legais. $O$ anonimato e confidencialidade das informações foram mantidos nos registros dos dados.

\section{RESULTADOS}

O resultado da temperatura média do ambiente de trabalho avaliado foi de $11,2^{\circ} \mathrm{C}$, a velocidade média do ar encontrada foi $0,26 \mathrm{~m} / \mathrm{s}$ e umidade relativa média de $80 \%$. A temperatura média do produto manipulado foi $4,9^{\circ} \mathrm{C}$ na peça de do 
frango. A temperatura média do cabo da faca foi $9,2^{\circ} \mathrm{C}$ e a temperatura média do piso da sala foi de $10,8^{\circ} \mathrm{C}$.

Com relação às temperaturas da mão que manuseia a faca, da mão que segura o produto e do pé avaliado de cada trabalhador no decorrer do estudo não foram encontradas diferenças significativas de cor, conforme representado na Figura 3 , através do resultado de cores nas imagens termográficas de um dos trabalhadores participante desse estudo.

Figura 3 - Imagem termográfica das mãos e do pé de um participante do estudo

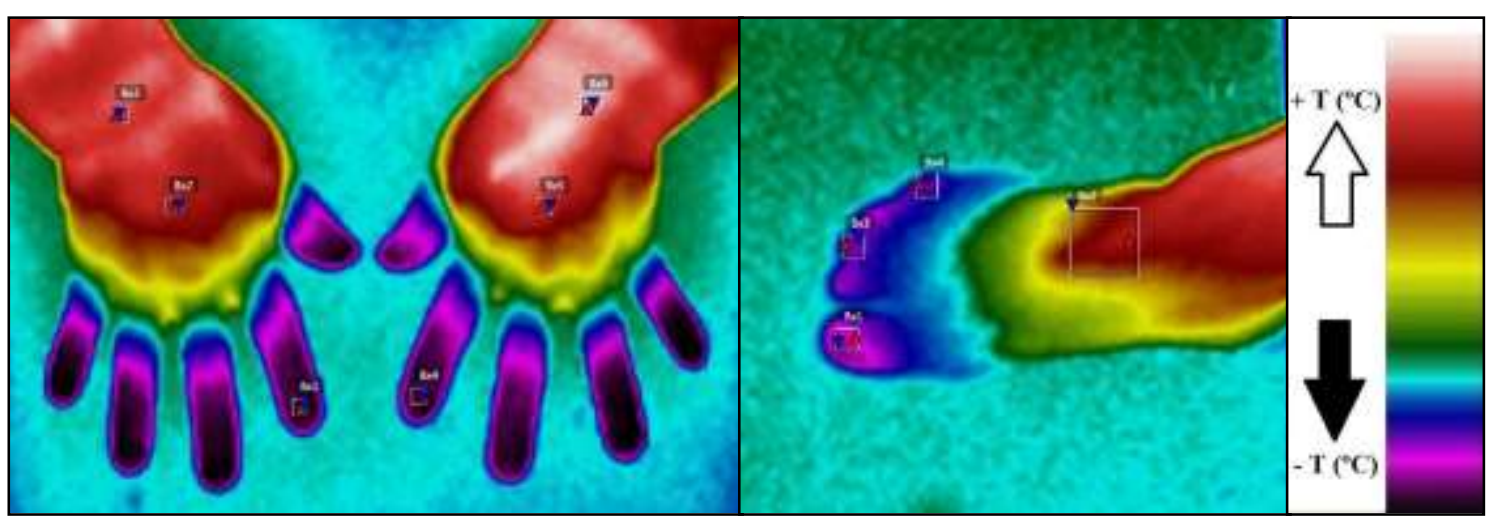

Fonte: Dados da pesquisa (2016)

Os resultados das imagens termográficas das mãos demonstram através do espectro de cores, que a região das extremidades dos dedos foi a que apresentou as menores temperaturas, representado pelo tom de cor violeta e as temperaturas no centro das mãos e punhos apresentam temperaturas representadas pela cor vermelha, com valores maiores em relação aos dedos.

Os resultados das imagens termográficas de cada pé avaliado demonstram que assim como ocorreu nas mãos, às extremidades dos dedos foram à região mais atingida pela exposição ao frio. As cores demonstram o tom de violeta nos dedos, e à medida que se aproxima do centro (navicular) do pé, percebe-se que a intensidade da temperatura aumenta conforme pode se ver representado pela cor vermelha na imagem do pé de um dos participantes do estudo.

Os dados da Tabela 1 representam os resultados das médias de temperaturas encontradas, assim como a sensação que pode ser percebida de acordo com a comparação do estudo de Lehmuskallio, Hassi e Kettunen (2002). 
Tabela 1 - Resultados das avaliações termográficas das mãos e pés

\begin{tabular}{|c|c|c|c|c|}
\hline $\begin{array}{c}\text { Região } \\
\text { do } \\
\text { corpo }\end{array}$ & $\begin{array}{l}\text { Sítio corporal } \\
\text { avaliado }\end{array}$ & $\begin{array}{c}\text { Número } \\
\text { de } \\
\text { amostras }\end{array}$ & $\begin{array}{l}\text { Média das } \\
\text { temperaturas } \\
\left({ }^{\circ} \mathrm{C}\right)\end{array}$ & $\begin{array}{c}\text { Lehmuskallio, } \\
\text { Hassi e } \\
\text { Kettunen } 40\end{array}$ \\
\hline \multirow{6}{*}{ Mãos } & Dedo/Faca & 10 & 16,86 & \multirow{3}{*}{$\begin{array}{c}\text { Dor } \\
\text { Dor } \\
\text { Desconforto } \\
\text { (Resfriado) }\end{array}$} \\
\hline & Dedo/Produto & 10 & 17,49 & \\
\hline & Centro/Faca & 10 & 27,27 & \\
\hline & Centro/Produto & 10 & 25,54 & $\begin{array}{l}\text { Desconforto } \\
\text { (Resfriado) }\end{array}$ \\
\hline & Punho/Faca & 10 & 28,54 & $\begin{array}{l}\text { Desconforto } \\
\text { (Resfriado) }\end{array}$ \\
\hline & Punho/Produto & 10 & 27,17 & $\begin{array}{l}\text { Desconforto } \\
\text { (Resfriado) }\end{array}$ \\
\hline \multirow{4}{*}{ Pés } & Hálux & 10 & 15,90 & Dor \\
\hline & $3^{\circ}$ metatarso & 10 & 16,30 & Dor \\
\hline & $5^{\circ}$ metatarso & 10 & 16,50 & \multirow{2}{*}{$\begin{array}{c}\text { Dor } \\
\text { Desconforto } \\
\text { (Frio) }\end{array}$} \\
\hline & Navicular & 10 & 24,10 & \\
\hline
\end{tabular}

Fonte: Dados da pesquisa (2016)

Verifica-se nos resultados que as menores temperaturas evidenciadas no estudo foi no hálux dos pés dos trabalhadores com valor de $15,90^{\circ} \mathrm{C}$ e nos dedos das mãos que segura a faca com $16,86^{\circ} \mathrm{C}$.

Com esses resultados é possível afirmar que as extremidades do corpo, mesmo protegidas por luvas, meias e botinas específicas para exposição ao frio, são as partes mais atingidas pelo frio, pois como pode perceber nos resultados à medida que se distância das extremidades, mais elevadas são as temperaturas.

Verifica-se que os resultados conforme comparados aos parâmetros estabelecidos no estudo de Lehmuskallio, Hassi e Kettunen (2002), nota-se que a condição que pode ser percebida pela maioria dos trabalhadores é a sensação de dor na região dos dedos do pé e dor na região dos dedos da mão que segura a faca e nas demais regiões avaliadas no estudo a condição é desconforto causado pelo frio.

\section{DISCUSSÃO}

Ressalta-se que apesar da temperatura do produto manuseado ser inferior a temperatura do cabo da faca, essa diferença acabou não impactando nos resultados 
de distribuição da temperatura entre as mãos, conforme ilustrado através da imagem termográfica da Figura 3.

Provavelmente esse efeito é suprido pela diferença de luvas utilizadas em ambas às mãos e/ou devido à estabilização térmica decorrente da exposição às baixas temperaturas do ambiente e dos materiais manipulados e utilizados.

Com relação ao atendimento as normas regulamentadoras e leis de saúde e segurança nacionais analisados no programa de prevenção de riscos ambientais (PPRA), laudo de insalubridade da empresa e critérios normativos atuais, no Quadro1 encontra-se os resultados e conclusões.

O que se conclui das condições levantadas no ambiente de trabalho nesse estudo comparado aos limites estabelecidos nas normas regulamentadoras e leis nacionais é que para todos os parâmetros estabelecidos para esse modelo de atividade as normas são atendidas, o que leva a concluir que a atividade avaliada nas condições apresentadas não causam danos à saúde dos trabalhadores e não são necessárias ações complementares de controle de acordo com as normas e leis nacionais de prevenção a riscos à saúde e integridade de trabalhadores expostos a baixas temperaturas enquadradas na faixa térmica similar a desse estudo.

A NR 15, com objetivo geral de estabelecer a condição "crítica" de uma atividade, pois seu objetivo é determinar as possíveis condições insalubres no desempenho de atividades, meramente fixa uma comparação qualitativa e subjetiva de ambientes de trabalho com exposição ao frio, não estabelece tempo de avaliação, não descreve tempo de exposição, faixas de temperatura mínimas, índices de isolamento térmico das roupas de acordo com a atividade e tempo de exposição, assim como a eficiência dos equipamentos e não descreve nenhuma relação entre temperaturas e possíveis doenças causadas pela exposição ao frio. Diante toda essa condição da norma regulamentadora NR 15, dificilmente os profissionais que promovem o controle de condições de risco a saúde do trabalhador detectarão utilizando apenas essa norma como parâmetro medidas que sejam eficientes para o controle de riscos à saúde dos trabalhadores dessa atividade avaliada. Conforme critérios comparativos a atividade avaliada atende essa norma com foco em condições insalubres, porém ao mesmo tempo verifica-se que as temperaturas mensuradas por meio da termográfia de imagens demonstram em comparação ao estudo de Lehmuskallio, Hassi e Kettunen (2002) que nessas 

pés.

Quadro 1 - Comparativo dos resultados com as normas e lei nacional para avaliação da exposição ao frio ocupacional (continua)

\begin{tabular}{|c|c|c|c|c|}
\hline Norma & $\begin{array}{l}\text { Método de } \\
\text { avaliação }\end{array}$ & Condição geral & $\begin{array}{c}\text { Resultado do } \\
\text { estudo }\end{array}$ & Conclusão \\
\hline NR 15 & $\begin{array}{l}\text { Método qualitativo } \\
\text { por enquadramento } \\
\text { do ambiente como } \\
\text { uma câmara } \\
\text { frigorífica ou } \\
\text { similaridade a uma } \\
\text { câmara frigorifica. }\end{array}$ & $\begin{array}{c}\text { De acordo com } \\
\text { documentos da empresa } \\
\text { (PPRA e Laudo de } \\
\text { Insalubridade), o } \\
\text { ambiente avaliado não é } \\
\text { classificado como uma } \\
\text { câmara, pois não se } \\
\text { destina a refrigeração de } \\
\text { produtos, e sim a } \\
\text { manipulação e cortes } \\
\text { específicos, local } \\
\text { refrigerado, porém não é } \\
\text { similar a uma câmara. }\end{array}$ & $\begin{array}{c}\text { Temperatura da } \\
\text { sala com média } \\
\text { de } 11,2^{\circ} \mathrm{C} \text {, não } \\
\text { congela ou } \\
\text { refrigera } \\
\text { produtos no } \\
\text { local. }\end{array}$ & $\begin{array}{l}\text { Atende a norma, } \\
\text { portanto não é } \\
\text { considerado um } \\
\text { ambiente Insalubre } \\
\text { de acordo com o } \\
\text { critério de avaliação } \\
\text { estabelecido na } \\
\text { norma } \\
\text { regulamentadora. }\end{array}$ \\
\hline NR 29 & $\begin{array}{c}\text { Avaliação da } \\
\text { temperatura do } \\
\text { ambiente por } \\
\text { termômetro de bulbo } \\
\text { seco e } \\
\text { enquadramento do } \\
\text { tempo de pausa para } \\
\text { recuperação térmica } \\
\text { fora do ambiente frio } \\
\text { de acordo com o } \\
\text { mapa oficial do IBGE. }\end{array}$ & $\begin{array}{c}\text { A menor temperatura } \\
\text { para usufruir de pausas } \\
\text { para recuperação } \\
\text { térmica estabelecidas } \\
\text { nessa norma é } \\
\text { temperaturas menores a } \\
+10^{\circ} \mathrm{C} \text { para uma } \\
\text { empresa localizada na } \\
\text { zona climática } \\
\text { mesotérmica, de acordo } \\
\text { com o mapa oficial do } \\
\text { IBGE. }\end{array}$ & $\begin{array}{l}\text { Temperatura } \\
\text { média da sala é } \\
\text { de } 11,2^{\circ} \mathrm{C} \text {. }\end{array}$ & $\begin{array}{l}\text { Atende a norma } \\
\text { sem necessidade } \\
\text { de pausas para } \\
\text { recuperação } \\
\text { térmica. }\end{array}$ \\
\hline NR 36 & $\begin{array}{c}\text { Avaliação da } \\
\text { temperatura do } \\
\text { ambiente por } \\
\text { termômetro de bulbo } \\
\text { seco e } \\
\text { enquadramento do } \\
\text { tempo de pausa para } \\
\text { recuperação térmica } \\
\text { fora do ambiente frio } \\
\text { de acordo com o } \\
\text { mapa oficial do IBGE. }\end{array}$ & $\begin{array}{l}\text { Utiliza o critério do artigo } \\
253 \text { da CLT descrito no } \\
\text { próximo item. }\end{array}$ & $\begin{array}{l}\text { Temperatura } \\
\text { média da sala é } \\
\text { de } 11,2^{\circ} \mathrm{C}\end{array}$ & $\begin{array}{l}\text { Atende a norma } \\
\text { sem necessidade } \\
\text { de pausas para } \\
\text { recuperação } \\
\text { térmica. }\end{array}$ \\
\hline $\begin{array}{l}\text { Artigo } \\
253 \text { da } \\
\text { CLT }\end{array}$ & $\begin{array}{c}\text { Avaliação da } \\
\text { temperatura do } \\
\text { ambiente por } \\
\text { termômetro de bulbo } \\
\text { seco e } \\
\text { enquadramento do } \\
\text { tempo de pausa para } \\
\text { recuperação térmica } \\
\text { fora do ambiente frio } \\
\text { de acordo com o } \\
\text { mapa oficial do IBGE. }\end{array}$ & $\begin{array}{l}\text { A menor temperatura } \\
\text { para usufruir de pausas } \\
\text { para recomposição } \\
\text { térmica estabelecidas } \\
\text { nessa norma é }+10^{\circ} \mathrm{C} \\
\text { para uma empresa } \\
\text { localizada na zona } \\
\text { climática mesotérmica, } \\
\text { de acordo com o mapa } \\
\text { oficial do IBGE. }\end{array}$ & $\begin{array}{l}\text { Temperatura } \\
\text { média da sala é } \\
\text { de } 11,2^{\circ} \mathrm{C}\end{array}$ & $\begin{array}{l}\text { Atende a Lei sem } \\
\text { necessidade de } \\
\text { pausas para } \\
\text { recuperação } \\
\text { térmica. }\end{array}$ \\
\hline
\end{tabular}


Quadro 1 - Comparativo dos resultados com as normas e lei nacional para avaliação da exposição ao frio ocupacional

\begin{tabular}{|c|c|c|c|c|}
\hline Norma & $\begin{array}{c}\text { Método de } \\
\text { avaliação }\end{array}$ & Condição geral & $\begin{array}{l}\text { Resultado do } \\
\text { estudo }\end{array}$ & Conclusão \\
\hline NR 09 & $\begin{array}{l}\text { Descreve que na } \\
\text { ausência de valores } \\
\text { limites de exposição } \\
\text { ocupacional ou } \\
\text { quando os limites } \\
\text { excedem a NR 15, } \\
\text { deverão ser adotados } \\
\text { valores da ACGIH. }\end{array}$ & $\begin{array}{c}\text { Considera que } \\
\text { temperaturas acima de } \\
+4 \text { o } \mathrm{C} \text { com velocidade do } \\
\text { vento calmo, ou seja, } \\
\text { abaixo de } 2,24 \mathrm{~m} / \mathrm{s} \text { os } \\
\text { riscos a saúde são } \\
\text { baixos. }\end{array}$ & $\begin{array}{l}\text { Temperatura } \\
\text { média da sala é } \\
\text { de } 11,2^{\circ} \mathrm{C} \\
\text { Velocidade } \\
\text { média do vento } \\
\text { de } 0,26 \mathrm{~m} / \mathrm{s} \text {. }\end{array}$ & $\begin{array}{l}\text { Atende a norma. } \\
\text { Sugere apenas a } \\
\text { necessidade do uso } \\
\text { de luvas devido à } \\
\text { temperatura } \\
\text { estarem abaixo de } \\
16^{\circ} \mathrm{C} \text { para } \\
\text { atividades } \\
\text { sedentárias. }\end{array}$ \\
\hline
\end{tabular}

Fonte: NR15; NR 29; NR 36, NR 09; Artigo 253 da CLT e dados da pesquisa (2016)

A norma regulamentadora NR 29 apesar de fixar faixas de temperatura com máxima exposição diária permissível descreve em seu texto que para cumprir os tempos de pausas para recuperação térmica, as pessoas expostas ao frio devem estar adequadamente vestidas, porém não há especificação de qual índice de resistência térmica é necessário para enquadrar como adequadamente vestido, tampouco o tipo de atividade desempenhada com exposição ao frio.

Não cita especificação de tempo necessário para mensuração do risco e acompanhamento da temperatura, não sugere temperaturas mínimas como parâmetros nas partes mais atingidas pelo frio e não descreve nenhum tipo de nexo entre exposição ao frio ocupacional e possíveis doenças. Considerando que as avaliações foram realizadas com exposições de tempo de 1 (uma) hora e 40 (quarenta) minutos de trabalho contínuo, nota-se que o atendimento dessa norma não seria suficiente para o controle da sensação de dor e desconforto causado pelo resfriamento nas regiões mais atingidas pelo frio.

A norma regulamentadora NR 36 com foco em preservar a saúde e segurança do trabalhador de empresas de processamento de carnes e derivados, criada no ano de 2013 menciona em seu texto o uso do artigo 253 da CLT, criado pelo Decreto Lei no 5.452 de 01 de Maio de 1943, a norma é a mais recente, porém usa o mesmo critério já existente a mais de 73 anos considerando a data atual, o qual especificamente determina que em condições de exposição ao frio apenas considerando as faixas climáticas do mapa do IBGE podem expor os trabalhadores a 1 (uma) hora e 40 (quarenta) minutos de trabalho contínuo em condições de frio. artigo não sugere ou determina condições mínimas de temperatura em que o trabalhador possa estar exposto, não determina meios de proteção e não relaciona 
nexo de doenças e exposição ao frio. Da mesma forma que a condição da NR 29, pressupõe que 1 (uma) hora e 40 (quarenta) minutos de trabalho contínuo de exposição ao frio não é prejudicial a saúde da maioria dos trabalhadores expostos ao frio ocupacional, o que leva a concluir que os resultados de uma avaliação termográfica similar a realizada nesse estudo não são considerados para usufruir as pausas de recuperação térmica e que o tempo determinado de exposição ao frio no artigo 253 da CLT, em condições similares as levantadas nesse estudo não são possíveis de causar danos a saúde dos trabalhadores.

Para a determinação de tempo máximo de exposição ao frio apresentados nas NR 29, NR 36 e artigo 253 da CLT que definem exposição por faixas de temperaturas de acordo com clima do local, cabe ressaltar que de acordo com Geng (2001) em seu estudo cita em atividades que as temperaturas atendem normas específicas de higiene alimentar as condições são relativamente bem definidas e controladas resultando em temperaturas bem definidas com exposições a condições mais ou menos semelhantes um dia após outro. Nestas condições a temperatura climática não interfere na exposição diária ao frio dos trabalhadores. Ou seja, indiferente de qual será a condição climática externa, a temperatura interna da sala, em que expõe o trabalhador ao frio durante todo o seu tempo de atividade, apresentará irrelevante variação de temperatura devido a necessidade de atendimento da norma de higiene alimentar indiferente da região que esteja localizado a atividade.

A NR 09, norma específica para controle de riscos à saúde de trabalhadores não determina valor para comparação de condições de exposição ao frio e controle de saúde, sugere o uso da ACGIH na falta de limites de tolerância previstos na NR 15, que conforme já descrito nesse estudo, esta norma apenas faz comparação qualitativa por similaridade de ambiente. Considerando que o parâmetro de temperatura para atendimento dessa norma fica estabelecido pela ACGIH, devido à falta de um valor limite estabelecido na NR 09 e NR 15 e que conforme resultados, no modelo de atividade avaliado a temperatura e velocidade do ar é atendida, não é detectado que segundo as normas existem potenciais riscos a saúde do trabalhador.

As condições de resfriamento e dor levantadas na análise termográfica não são avaliadas pela ACGIH, que determina sintomas clínicos progressivos de 
hiportemia considerando temperatura interna do núcleo do corpo determinada por métodos convencionais de medição da temperatura retal).

Também na ACGIH há sugestão de proteção das mãos para preservar a destreza manual e consecutivamente prevenir acidentes em trabalhos de precisão com as mãos em temperaturas abaixo de $16^{\circ} \mathrm{C}$, porém essa temperatura é do ambiente de trabalho, o qual é superior a temperatura do ambiente em que as pessoas desse estudo foram avaliadas. Também descreve que atividades com exposição a temperaturas inferiores a $4^{\circ} \mathrm{C}$ deve ser fornecida roupa isolante seca para os trabalhadores. Porém essa condição de temperatura de $4^{\circ} \mathrm{C}$ não é encontrada nas atividades desse estudo, que conforme já descritas são de temperatura média de $11,2^{\circ} \mathrm{C}$.

Importante ressaltar que a ACGIH descreve que em atividades com exposição ao frio as dores nas extremidades do corpo podem ser o primeiro aviso de perigo para estresse pelo frio e que nessa condição o trabalho físico e mental é limitado. Também descreve que ao menos que ocorram situações excepcionais, é improvável que surjam lesões por frio em outras partes do corpo, além das mãos, pés e cabeça, sem o aparecimento de sintomas iniciais de hiportermia.

Os resultados das avaliações quantitativas comparadas às leis e normas regulamentadoras nacionais apresentam em resumo que para o modelo de atividade, o risco frio ocupacional não é considerado insalubre e não faz necessário aos períodos de pausa para recuperação térmica, assim como não determina possíveis ações para minimizar o impacto do frio e lesões aos trabalhadores, o que leva a concluir que o modelo de atividade avaliado, assim como similares a essa, considerando os parâmetros das normas regulamentadoras de saúde e segurança nacionais não conceitua a condição levantada como causadora de danos à saúde e integridade do trabalhador. Apenas na $A C G I H$, utilizada devido à falta de limites de tolerância nas normas regulamentadores NR 09 e NR 15, ressalta que na condição levantada nesse estudo é obrigatório o uso de luvas para proteção dos trabalhadores em atividades com temperaturas abaixo de $16^{\circ} \mathrm{C}$ para trabalhos sedentários, porém nada cita para proteção dos pés dos trabalhadores que de acordo com os resultados obteve temperaturas menores do que as temperaturas encontradas nas mãos. 
Considerando os resultados da avaliação termográfica comparados aos critérios do estudo de Lehmuskallio, Hassi e Kettunen (2002), demonstram que a condição é propicia a encontrar trabalhadores com as mãos e pés com sensação de resfriamento e dor, demonstrando que as condições são de exposição a possíveis lesões e doenças causadas pelo frio e que necessitam de medidas que minimizem ou neutralizem o impacto do frio devido ao resfriamento das regiões avaliadas.

Para reforçar essa condição de risco a saúde e integridade das pessoas expostas a ambientes similares apresentadas nesse estudo, pode-se citar o estudo realizado por Holmér (1994) o qual afirma que temperaturas dos dedos abaixo das condições de conforto, ou seja, similares às analisadas nesse estudo, ocasionalmente podem ser aceitáveis, pois temperaturas abaixo da condição de conforto gera prejuízo à força, destreza e coordenação, bem como aumenta a incidência de queixas relacionadas à sensação de dor e condições de acidentes.

Ilmarinen e Tammela (1990) relatam em seu estudo onde foi observado que trabalhadores sem proteção adequada para as mãos, expostos ao frio de uma sala de cortes de um matadouro, com temperatura média da sala de $10^{\circ} \mathrm{C}$, condição de temperatura da sala similar a desse estudo, encontravam-se trabalhadores com temperaturas médias dos dedos entre $17-12^{\circ} \mathrm{C}$, e que sobre estas condições, para os pesquisadores, é difícil manter o equilibrio térmico do corpo, aumentando o risco de acidentes devido o resfriamento e dormência dos dedos que causam rigidez dos dedos e mãos, perda da destreza manual e redução da força muscular.

Ressalta-se que diferente do estudo realizado por Ilmarinen e Tammela (1990) nesse estudo os trabalhadores utilizaram luvas de proteção fornecidas pela empresa para exposição ao frio, no entanto as temperaturas encontradas nos dedos encontram-se em faixas de temperatura próximas as encontradas no estudo de Ilmarinen e Tammela (1990) o que leva a concluir que as luvas não parecem ser apropriadas para essa condição de atividade e temperatura. Baseado neste resultado pode-se supor que mesmo utilizando as luvas de proteção fornecidas pela empresa, que possuem certificado de aprovação para o risco frio e que supostamente atendem aos requisitos da $\mathrm{ACGIH}$, possivelmente os trabalhadores estejam expostos aos mesmos problemas de saúde e risco de acidentes e danos à saúde citados no estudo de llmarinen e Tammela (1990). 
Embora as normas nacionais fixem valores limites de tolerância para o ambiente de trabalho, estudos realizados em ambientes similares, com temperaturas próximas a $10^{\circ} \mathrm{C}$ demonstram que podem causar danos à saúde dos trabalhadores. $\mathrm{Na}$ pesquisa de Thetkathuek et. al. (2015) foram avaliados 497 trabalhadores expostos ao frio em indústrias de processamento de alimentos na Tailândia no qual os resultados apontam que os trabalhadores apresentam problemas de dores musculares nas costas, problemas respiratórios, condições de resfriamento dos dedos e sintomas cardiovasculares.

Também demonstra condição de dano à saúde o estudo realizado por Kaminski et. al. (1997) no qual foram coletados dados de 1474 trabalhadores franceses de 17 abatedouros de aves e 06 fábricas de conservas no período de 1987-1988, demonstram com os resultados que são possíveis em uma população de homens e mulheres expostos ao frio, sem vibração, detectar fatores de risco para o fenômeno de Raynaud.

Estes são alguns estudos em que condições similares a desse estudo os pesquisadores detectaram possíveis danos a saúde em trabalhadores expostos a baixas temperaturas sem as devidas medidas de controle que preservam a integridade e saúde dos trabalhadores.

Enfim, os resultados desse estudo apontam que se tratando de condições que preservam a saúde ocupacional e a integridade de trabalhadores o foco deve ser as condições em que o trabalhador se encontra no desenvolvimento de suas atividades no ambiente de trabalho e não meramente as condições do ambiente e principalmente no caso do risco físico frio é imprescindível verificar as consequências das temperaturas do ambiente vinculadas ao modelo de atividade e equipamentos utilizados e suas consequências na temperatura corporal do trabalhador, condição que pode ser verificada com o uso da avaliação termográfica.

De posse dos dados que a avaliação termográfica infravermelha pode oferecer nesse estudo, fica evidente que seu uso é eficiente e prático para a análise do risco o qual demonstra a necessidade de melhorias neste modelo de atividade analisado e principalmente nas normativas nacionais em estabelecer valores limites de temperaturas que garantam condições propicias para saúde e segurança de pessoas que trabalham em ambientes com exposição ao frio. 


\section{CONSIDERAÇÕES FINAIS}

Os números de abatedouros e frigoríficos, de produção, de trabalhadores e consecutivamente lesões e doenças aumentam proporcionalmente de acordo com as estatísticas nacionais e as expectativas são de recordes para os próximos anos em produção. Além desses cabe ressaltar que outros modelos de atividades também expõem trabalhadores a temperaturas similares a desse estudo. Por outro lado as normativas e leis que podem de forma direta quando implementadas contribuir na redução e controle dos riscos a saúde e integridade física dos trabalhadores parece não evoluir na mesma proporção.

Com a termografia de imagens, método não descrito como forma de avaliação nas normas e leis nacionais de saúde e segurança do trabalhador foi possível quantificar as temperaturas em condições reais de trabalho, e não de forma qualitativa e subjetiva, permitindo resultados quantitativos que possibilitam suporte para ações de controle da exposição ao frio ocupacional.

Uma das implicações práticas que pode ser citada no uso da avaliação por meio de imagens termográficas é a falta de parâmetros de segurança e saúde do trabalho para exposição ocupacional ao frio pela legislação brasileira, que dificulta as ações a serem implantadas pelas empresas e confunde 0 entendimento dos profissionais de medicina e segurança do trabalho para manter condições propícias de trabalho em ambientes com exposição ao frio e por sua vez quem é prejudicado diretamente são os trabalhadores expostos às condições inseguras com parâmetros que supostamente são coerentes aos requisitos legais.

Por fim verifica-se a necessidade de criar e normatizar procedimentos de avaliação e controle de riscos para a exposição ao frio ocupacional principalmente considerando toda jornada de trabalho diária, pois se ressalta que neste estudo as avaliações foram realizadas em apenas um momento da jornada o qual não possibilita concluir que as condições levantadas nos resultados desse estudo sejam encontradas em toda jornada de trabalho.

\section{REFERÊNCIAS}

ACGIH - American Conference of Industrial Hygienists (ACGIH). Limites de exposição ocupacional (TLVs) para substâncias químicas e agentes físicos \& Índices biológicos 
de exposição (BEls). Tradução: Associação Brasileira de Higienistas Ocupacionais (ABHO), 2015.

ARAUJO AFDV et al. Identificação de fatores de riscos ocupacionais no processo de abate de bovinos. Cadernos de Pesquisa, v. 19, n. 3, p. 79-89, 2013.

ARMSTRONG J. et al. A conceptual model for workrelated neck and upper-limb musculoskeletal disorders. Scand J Work Environ Health, v. 19, n. 2, p. 73-84, 1993. https://doi.org/10.5271/sjweh.1494

ARTIGO 253, § 1 Consolidação das Leis do Trabalho - Decreto Lei 5452/43. Constituição 1988. Constituição da República Federativa do Brasil. Brasília(DF): Senado;

ASSUNÇÃO A; ALMEIDA, IM. Doenças osteomusculares relacionadas com o trabalho: membro superior e pescoço. 2. ed. São Paulo: Atheneu, 2003.

BAO S, SILVERSTEIN B, COHEN M. An electromyography study in three high risk poultry processing jobs. International Journal Of Industrial Ergonomics, [s.I.], v. 27, n. 6, p.375385, jun. 2001. Elsevier BV. Disponível em:

<http://api.elsevier.com/content/article/PII:S016981410100004X?httpAccept=text/xml>. Acesso em: 23 jun. 2016. https://doi.org/10.1016/S0169-8141(01)00004-X

BONDE JP. et al. Prognosis of shoulder tendonitis in repetitive work: a follow up study in a cohort of Danish industrial and service workers. Occup Environ Med, n. 60, p.E8, 2003. https://doi.org/10.1136/oem.60.9.e8

BUZANELLO, MR. Influência de variáveis ambientais em frigorífico da unidade climática Subtropical Sul sobre os trabalhadores expostos a baixas temperaturas. 2003. 132 f. Dissertação (Mestrado) - Curso de Engenharia de Produção, Centro Tecnológico, Universidade Tecnológica Federal do Paraná, Florianópolis, 2003.

BUSNELLO GF, DEWES M. Doenças Osteomusculares Relacionadas à Atividades de Trabalhadores de Frigoríficos de Frangos. Brazilian Journal Of Surgery And Clinical Research - Bjscr, Maringá, v. 4, n. 3, p.27-32, 9 set. 2013. Disponível em: <http://www.mastereditora.com.br/bjscr>. Acesso em: 15 jun. 2016.

BUZANELO MR; MORO ARP. Slaughterhouse workers exposed to cold: proposal of reference thermography values for hands. Work, v. 41, p. 2876-2881, 2012.

CASO MA, RAVAIOLI M, VENERI L. Esposizione a sovraccarico biomeccanico degli arti superiori: la valutazione del rischio lavorativo nei macelli avicoli. Prevenzione Oggi, v. 3, n. 4, p. 9-21, 2007.

CASTRO TR, OKAWA CP. Auditoria de segurança e saúde do trabalho em uma indústria de alimentos do estado do Paraná. Revista Produção Online, v. 16, n. 2, p. 678-704, 2016. https://doi.org/10.14488/1676-1901.v16i2.2063

DEJOURS, C; ABDOUCHELI, e; JAYET, C. Psicodinâmica do trabalho. São Paulo: Atlas, 1994.

FROST P, ANDERSEN JH, NIELSEN Vk. Occurrence of carpal tunnel syndrome among slaughterhouse workers. Scand J Work Environ Health, [s.I.], v. 24, n. 4, p.285-292, ago. 1998. https://doi.org/10.5271/sjweh.322 
GENG, Q. Hand Cooling, Protection and Performance in Cold Environment: National Institute for Working Life. 2001. 71 f. Tese (Doutorado) - Curso de Division Of Industrial Ergonomics, Department Of Human Work Sciences, Luleå University Of Technology, Suécia, 2001. Disponível em: <https://gupea.ub.gu.se/bitstream/2077/4270/1/ah2001_04.pdf>. Acesso em: 20 jun. 2016.

HASSI J. et al. The pituitary-thyroid axis in healthy men living under subarctic climatological conditions. J Endocrinol, v. 169, n. 1, p. 195-203, 2001. https://doi.org/10.1677/joe.0.1690195

HECK FM. Uma geografia da degradação do trabalho: o adoecimento dos trabalhadores em Frigoríficos. Revista Percurso. Maringá, v. 5, n. 1, p. 03-31, 2013.

HOLMÉR I. Cold stress: Part II - The scientific basis (knowledge base) for the guide. Int $\mathbf{J}$ Ind Ergon, v. 14, p. 151-159, 1994. https://doi.org/10.1016/0169-8141(94)90012-4

IIDA I. Ergonomia: projeto e produção. 2. ed. São Paulo: Bluscher, 2005. 614 p.

ILMARINEN RE, TAMMELA EK. Design of functional work clothing for meat-cutters. Applied Ergonomics , v. 21, n. 1, p. 2-6, 1990. https://doi.org/10.1016/0003-6870(90)90067-8

INSTITUTO BRASILEIRO DE GEOGRAFIA E ESTATÍSTICA (IBGE). Base de dados agregados (SIDRA) Pesquisa Trimestral do Abate de Animais (2016). Disponível em: http://www.sidra.ibge.gov.br/bda/tabela/listabl.asp?c=1093\&z=t\&o=24. (Acessado em: 16/jan/2016).

JAKOBI HR. et al. Benefícios auxílio-doença concedidos aos trabalhadores empregados no ramo de carne e pescado no Brasil em 2008. Cad. Saúde Pública, Rio de Janeiro, v. 31, n. 1, p.194-207, 2015.

JUUL-KRISTENSEN B. et al. Physical workload during manual and mechanical deboning of poultry. International Journal Of Industrial Ergonomics, [s.I.], v. 29, n. 2, p.107-115, fev. 2002. Elsevier BV. https://doi.org/10.1016/S0169-8141(01)00051-8. Disponível em: <http://api.elsevier.com/content/article/PII:S0169814101000518?httpAccept=text/xml>. Acesso em: 24 jun. 2016.

KAMINSKI M. et al. Risk factors for raynaud's phenomenon among workers in poutry slaughterhouses and canning factories. International Journal Epidemiology, v. 26, n. 2, p. 371-380, 1997. https://doi.org/10.1093/ije/26.2.371

LAKATOS EM; MARCONI MA. Técnicas de pesquisa. São Paulo: Atlas, 2007.

LEHMUSKALLIO E, HASSI J, KETUNEN P. The skin in the cold. Int $\mathbf{J}$ Circumpolar Health, v. 61 , p. 277-286, 2002. https://doi.org/10.3402/ijch.v61i3.17475

MINISTÉRIO DA AGRICULTURA PECUÁRIA E ABASTECIMENTO (MAPA) Aves (2016). Disponível em: http://www.agricultura.gov.br/animal/especies/aves. Acessado em: 18 jan. 2016.

MINISTÉRIO DA PREVIDÊNCIA SOCIAL. Anuário estatístico de acidentes de trabalho AEAT Infologo (base de dados históricos de acidentes de trabalho). Disponível em: http://www3.dataprev.gov.br/aeat/ (Acessado em: 12/jan/2016).

MINISTÉRIO DO TRABALHO E EMPREGO. NR 09: programa de prevenção de riscos ambientais. 77. ed. São Paulo: Atlas, 2016. 
MINISTÉRIO DO TRABALHO E EMPREGO. NR 15: atividades e operações insalubres. 77 ed. São Paulo: Atlas, 2016.

MINISTÉRIO DO TRABALHO E EMPREGO. NR 29: segurança e saúde no trabalho portuário. 77 ed. São Paulo: Atlas, 2016.

MINISTÉRIO DO TRABALHO E EMPREGO. NR 36: segurança e saúde no trabalho em empresas de abate e processamento de carnes e derivados. 77 ed. São Paulo: Atlas, 2016.

MUSOLIN K. et al. Prevalence of carpal tunnel syndrome among employees at a poultry processing plant. Applied Ergonomics, [s.I.], v. 45, n. 6, p.1377-1383, nov. 2014. Elsevier BV. https://doi.org/10.1016/j.apergo.2014.03.005. Disponível em: <http://api.elsevier.com/content/article/PII:S0003687014000398?httpAccept=text/xml>. Acesso em: 24 jun. 2016.

Portaria no 210 de 10/11/1998. Dispõe sobre o regulamento técnico da inspeção tecnológica e higiênico-sanitária de carnes de aves. Diário Oficial da União, Brasília, 26/nov/1998.

QUEIROZ MF, MACIEL RH. Condições de trabalho e automação: o caso do soprador da indústria vidreira. Revista de Saúde Pública, v. 35, n. 1, p. 1-9, 2001.

https://doi.org/10.1590/S0034-89102001000100001

REIS, PF. O trabalho repetitivo em frigorífico: utilização da estesiometria da mão como proposta para avaliação dos níveis de LER/DORT nas síndromes compressivas dos membros superiores. 2012. 137 f. Tese (Doutorado) - Curso de Engenharia de Produção, Centro Tecnológico, Universidade Federal de Santa Catarina, Florianopolis, 201. Disponível em: <https://repositorio.ufsc.br/bitstream/handle/123456789/100528/308795.pdf?>. Acesso em: 23 abr. 2016.

SARDÁ SE, RUIZ RS, KIRTSCHIG G. A Tutela Jurídica da Saúde dos Empregados de Frigoríficos: Considerações dos Serviços Públicos. Acta Fisiatr , v. 16, n. 2, p. 59-65, 2009.

SOMMERICH CM, MCGLOTHLIN JD, MARRAS WS. Occupational risk factors associated with soft tissue disorders of the shoulder: a review of recent investigations in the literature.Ergonomics, [s.I.], v. 36, n. 6, p.697-717, jun. 1993. Informa UK Limited. https://doi.org/10.1080/00140139308967931

SUNDSTRUP E. et al. Participatory ergonomic intervention versus strength training on chronic pain and work disability in slaughterhouse workers: study protocol for a single-blind, randomized controlled trial. Bmc Musculoskeletal Disorders, [s.I.], v. 14, n. 1, p.67-79, 2013. Springer Science + Business Media. DOI: 10.1186/1471-2474-14-67. https://doi.org/10.1186/1471-2474-14-67

SUNDSTRUP E. et al. High Intensity Physical Exercise and Pain in the Neck and Upper Limb among Slaughterhouse Workers: Cross-Sectional Study. Hindawi Publishing Corporation: BioMed Research International. New York, p. 1-6. 09 jan. 2014. Disponível em: <http://dx.doi.org/10.1155/2014/218546>. Acesso em: 20 mar. 2015.

THETKATHUEK A. et al. Cold exposure and health effects among frozen food processing workers in eastern Thailand. Safety and Health at Work, v. 6, p. 56-61, 2015.

https://doi.org/10.1016/j.shaw.2014.10.004 
União Brasileira de Avicultura (UBABEF). Exportações brasileiras de carne de frango têm volume recorde para março, diz associação (2016). Disponível em:

http://www.abef.com.br. (Acessado em: 10/jan/2016).

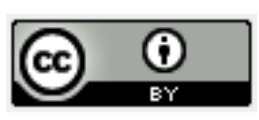

Artigo recebido em 17/09/2016 e aceito para publicação em 05/10/2017

DOI: http://dx.doi.org/10.14488/1676-1901.v17i4.2577 